АН СССР. Сер. 3. Геоботаника. М., 1950. Вып. 6. гии и химии: мат-лы всерос. конф. Йошкар-Ола:

C. 7-204.

23. Уранов А.А. Возрастной спектр фитоценопопуляций как функция времени и энергетических волновых процессов // Биологические науки. 1975. № 2. С. 7-34.

24. Гаранина Е.В., Рябинина С.А., Суетина Ю.Г. Оценка микроклиматических условий в разных местообитаниях эвернии сливовой (Evernia prunastri (L.) Ach.) //Актуальные проблемы экологии, биоло-
Мар. гос. ун-т, 2010. С. 163-165.

25. Johansson V., Bergman K.-O., Lättman H., Milberg $\mathrm{P}$. Tree and site quality preferences of six epiphytic lichens growing on oaks in southeastern Sweden // Ann. Bot. Fenn. 2009. Vol. 46, № 6. P. 496-506.

Статья публикуется при поддержке гранта РФФИ (№ 16-04-0119 a).

\title{
ONTOGENETIC VARIABILITY OF MORPHOLOGICAL CHARACTERS OF EVERNIA PRUNASTRI (L.) ACH. ON DIFFERENT SPECIES OF TREES IN DIFFERENT ECOLOGICAL CONDITIONS
} (C) 2017

\author{
Suetina Yulia Gennadjevna, candidate of biological sciences, associate professor of Biology Department \\ Mari State University (Yoshkar-Ola, Russian Federation)
}

\begin{abstract}
The current paper is about the morphological characters variability of the epiphytic lichen Evernia prunastri. The studies were conducted on the territory of the Mari El Republic in the flooded lime-tree forest of the Bolshaya Kokshaga river. The thalli of $E$. prunastri of different ontogenetic states $\left(\mathrm{v}_{1}, \mathrm{v}_{2}, \mathrm{~g}_{1} \mathrm{v}, \mathrm{g}_{2} \mathrm{v}, \mathrm{g}_{3} \mathrm{v}\right.$, ss) were collected on Tilia cordata, Padus avium, Quercus robur at a stem height of 0,5 to $2 \mathrm{~m}$ and on Abies sibirica branches at heights of 3-4 m, 5-6 m, 7-8 m. Tilia cordata is the most favorable substrate for the development of E. prunastri thalli for most of its characters. The character of the thallus development (the length of the thallus) is minimal in Padus avium. The characters of death (the number of dead branches, the length of the cortex blackening area) are maximal on Padus avium, which indicates more accelerated aging processes of the thallus in this phorophyte. The thallus of E. prunastri, which grows on the branches of Abies sibirica, has the largest lengths at heights of 3-4 and 5-6 $\mathrm{m}$ in comparison with the height of 7-8 $\mathrm{m}$. At higher altitudes, longer soralia are formed, hence, more soredia are formed. The values of most characters of E. prunastri, which grows on the right bank of the Bolshaya Kokshaga river are bigger than on the left bank, which is due to differences in the lighting of habitats. The length of the soralia on the right bank (the best lighting) is more in Quercus robur than in Tilia cordata. The variability of morphological characters is manifested in different ways in different ontogenetic states.

Keywords: epiphytic lichen; fruticose lichen; Evernia prunastri; substrate; phorophyte; tree trunk; tree branches; Abies sibirica; Quercus robur; Tilia cordata; Padus avium; ontogeny; ontogenetic states; morphological characters; variability; fitness; ecological conditions; flooded lime-tree forest; Bolshaya Kokshaga river; Mari El Republic.
\end{abstract}

УДК 502.504

Статья поступила в редакцию 04.10.2017

\section{ОЦЕНКА ВОЗДЕЙСТВИЯ НЕФТЕГАЗОДОБЫВАЮЩЕГО ПРЕДПРИЯТИЯ НА ЭКОЛОГИЧЕСКОЕ СОСТОЯНИЕ ПОЧВ БЛИЗЛЕЖАЩЕЙ ТЕРРИТОРИИ}

(C) 2017

Султанова Миляуша Ильнуровна, студент факультета биологии и химии

Шмелёв Николай Александрович, кандидат биологических наук, доцент кафедры биологии и экологии

Исламова Айсылу Айратовна, кандидат биологических наук, доцент кафедры биологии и экологии Бирский филиал Башкирского государственного университета (2. Бирск, Республика Башкортостан, Российская Федераџия)

Аннотация. В статье анализируются результаты исследования почвенного слоя на территории нефтегазодобывающего предприятия. Оценка техногенного воздействия нефти на основные химические и биологические показатели почв дана на основании экспериментальных исследований на территории предприятия. Объектами изучения послужили фоновые (незагрязненные) и загрязненные нефтью почвы. Влияние загрязнения нефтью в природных условиях изучали с помощью сопоставления свойств загрязненных почв с их фоновыми аналогами. Почвенный покров - основной элемент ландшафта - первым принимает на себя «экологический удар». В связи с механическим нарушением и нередко химическим загрязнением происходит постепенная деградация почв, которая стала одной из основных экологических проблем нефтегазодобывающего комплекса. Исследования проводились в апреле - мае 2017 года. В ходе анализа видно, что значительно изменились морфологические признаки почвы. Анализ фитотоксичности почвы с помощью метода биотестирования с применением семян кресс-салата показал высокую степень фитотоксичности почв. Процент гумуса оказался значительно ниже среднего содержания в верхнем горизонте почв. Анализ результатов химического состава показал, что уровень загрязнения почвы тяжелыми металлами низкий, за исключением концентраций кадмия и кобальта. Содержание нефтепродуктов также не превышает ПДК.

Ключевые слова: почвенный слой; нефтегазодобывающее предприятие; структура почвы; лабораторные исследования; сравнительный анализ; тяжелые металлы; морфологические признаки почвы; нефтепродукты; фитотоксичность; кресс-салат; метод биоиндикации; физико-химические методы анализа; предельно допустимая концентрация. 


\section{Введение}

Нефтегазовые предприятия оказывают негативное влияние на все компоненты окружающей среды без исключения. Основные загрязняющие вещества это углеводороды, сероводород, оксиды углерода, диоксид серы, и азот. В целом выбросы предприятий нефтехимической отрасли содержат до 240 химических веществ, треть из которых представляет I и II класс опасности $[1 ; 2]$.

Загрязнение природной среды традиционно контролируют путем физико-химических, физических и химических методов анализа проб воздуха, воды, почвы, биологических объектов и сравнения содержания в этих объектах загрязняющих веществ с фоновыми концентрациями или установленными гигиеническими нормативами (ПДК, ОДК).

Из трех основных составляющих природных сред - почвы, воды и воздуха - сложнее всего восстанавливаются загрязненные почвы, поскольку способны аккумулировать и закреплять токсические вещества. Естественное восстановление почв, загрязненных нефтью, - чрезвычайно медленный процесс. При высоком уровне загрязнения (например, при разливах нефти) происходит практически полная депрессия функциональной активности флоры и фауны, ингибируется жизнедеятельность большинства микроорганизмов [3] и происходит угнетение самоочищающей способности почвы [4].

\section{Материалы и методы исследования}

Исследования проводились в апреле - мае 2017 г. Их целью являлось проведение возможной оценки фитотоксичности почвы, исследование химического состава почвенного слоя вблизи нефтегазодобывающего предприятия и определение степени загрязненности почвы методом биотестирования [5]. Методы исследования: маршрутно-экспедиционный, физикохимические методы анализа, метод биотестирования [6].

Отбор проб был произведен в соответствии с общими требованиями отбора проб (ГОСТ 17.4.4.0284) [7]. Определение массовых концентраций тяжелых металлов осуществлялось атомно-абсорбционным методом на спектрометре КВАНТ-Z.ЭТА. Химический анализ состава почвенного покрова проводился в лаборатории мониторинга физико-химических загрязнений окружающей среды при Бирском филиале Башкирского государственного университета, г. Бирск (Республика Башкортостан).

Степень загрязненности территорий исследования оценивалась исходя из состояния почвенного покрова. Объектом исследований послужили пробы почвы, взятые с различных по загрязненности территорий.

В качестве мест отбора проб были выбраны места: с территории нефтегазодобывающего предприятия (образец № 1), в 150 метрах от предприятия (образец № 2), с территории частного земельного участка (в 1 км от предприятия) (образец № 3).

\section{Результаты исследования и их обсуждение}

Почва, выполняя свои экологические функции, обеспечивает стабильность отдельных биогеоценозов и биосферы, поэтому мониторинг состояния почв имеет большое значение. Загрязнение нефтью влияет Оценка воздействия нефтегазодобывающего предприятия..

на весь комплекс физических, морфологических, биологических, физико-химических свойств почвы, определяющих еe экологические и плодородные функции. Изменение свойств почвы при загрязнении нефтью, а также процессы ее миграции, аккумуляции и метаболизма зависят от физико-химического состава и количества пролитой нефти, почвенноклиматических и ландшафтных условий, типа почвы, наличия тех или иных биохимических барьеров, каналов миграции и диффузии в почвенном профиле $[8 ; 9]$.

При анализе пробы, отобранной с территории предприятия, были рассмотрены внешние показатели. Прежде всего, значительно изменились морфологические признаки почвы. Загрязненная проба почвы имеет более темный цвет по сравнению с более чистыми аналогами, повышенную плотность, отличается наличием маслянистых и радужных пленок по граням структурных отдельностей в иллювиальных горизонтах, появлением столбчатой структуры в нижней части профиля [10].

Был проведен анализ фитотоксичности почвы с помощью метода биотестирования с применением семян кресс-салата (Lepidium sativum) [11; 12].

Полученные данные были соотнесены с требованиями ГОСТа 12038-84 [13]. Согласно вышеуказанному документу, снижение числа проростков в опытном варианте по сравнению с контрольным на $10-30 \%$ говорит о слабой фитотоксичности почвы. Разница от 30 до 50\% указывает на среднюю степень фитотоксичности почвы, а выше 50\% - свидетельствует о высокой (недопустимой) степени фитотоксичности почвы. Разница менее $10 \%$ не принимается во внимание - почва считается экологически чистой. Полученные результаты представлены в табл. 1.

таблица 1 - Всхожесть семян

\begin{tabular}{|c|c|c|c|c|c|c|c|}
\hline \multirow{2}{*}{ Проба } & \multirow{2}{*}{$\begin{array}{c}\text { Коли- } \\
\text { чество } \\
\text { поса- } \\
\text { жен- } \\
\text { ных } \\
\text { семян } \\
\text { (шт.) }\end{array}$} & \multicolumn{3}{|c|}{$\begin{array}{c}\text { Количество } \\
\text { проросших } \\
\text { семян, в течение } \\
10 \text { дней (шт.) }\end{array}$} & \multicolumn{3}{|c|}{$\begin{array}{c}\text { Процент } \\
\text { пророс- } \\
\text { ших } \\
\text { семян }(\%)\end{array}$} \\
\hline & & $\underset{m}{\stackrel{\theta}{O}}$ & $\begin{array}{l}\hat{\theta} \\
0 \\
0 \\
0\end{array}$ & $\begin{array}{l}\text { A } \\
0 \\
0 \\
0\end{array}$ & $\begin{array}{l}\text { 吾 } \\
\text { 怘 } \\
\text { m }\end{array}$ & $\begin{array}{l}0 \\
0 \\
0 \\
0 \\
0\end{array}$ & 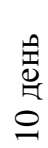 \\
\hline Образец № 1 & 50 & 5 & 16 & 16 & 10 & 32 & 32 \\
\hline Образец № 2 & 50 & 12 & 34 & 34 & 24 & 68 & 68 \\
\hline $\begin{array}{l}\text { Образец № } 3 \\
\text { (контроль) }\end{array}$ & 50 & 20 & 44 & 44 & 40 & 88 & 88 \\
\hline
\end{tabular}

Сравнительный анализ результатов эксперимента на третий день выявил следующее. В образце № 1 проросли лишь 10\%, проростки были слабые. Во втором - 24\%, они были уже выше, а в третьем контрольном образце взошло $40 \%$ семян, это на $30 \%$ больше, чем в пробе, взятой с территории предприятия. Проростки из последнего образца оказались более ровными, чем в остальных субстратах. На шестой день опыта процент всхожести повысился. В первом образце до $32 \%$, во втором - до $68 \%$, ростки были достаточно ровные и высокие, в третьем число ростков возросло до 88\%. Разница между пробой № 1 и пробой № 3 составила 56\%. К десятому дню 
эксперимента число взошедших семян не изменилось, соответственно, можно сделать вывод, что степень фитотоксичности почвы на территории предприятия недопустимо высока. Исходя из литературных данных, мы можем предположить, что изменение физических свойств почвы при загрязнении привело к вытеснению воздуха нефтью, нарушению поступления воды, питательных веществ, что является главной причиной торможения развития растений и их гибели [8; 14].

Таблица 2 - Результаты лабораторных исследований почвенного слоя

\begin{tabular}{|l|c|c|c|}
\hline $\begin{array}{c}\text { Определяемый } \\
\text { показатель }\end{array}$ & $\begin{array}{c}\text { Проба почвы } \\
150 \text { м от } \\
\text { предприятия }\end{array}$ & $\begin{array}{c}\text { С террито- } \\
\text { рии пред- } \\
\text { приятия }\end{array}$ & $\begin{array}{c}\text { ПДК } \\
{[15]}\end{array}$ \\
\hline Гумус, \% & $\begin{array}{c}2,7 \\
\pm 0,2\end{array}$ & $\begin{array}{c}0,6 \\
\pm 0,1\end{array}$ & $7-10$ \\
\hline $\begin{array}{l}\text { Нефтепродукты, } \\
\text { мг/кг }\end{array}$ & $\begin{array}{c}108,08 \\
\pm 21,62\end{array}$ & $\begin{array}{c}315,28 \\
\pm 47,86\end{array}$ & $\begin{array}{c}100- \\
500\end{array}$ \\
\hline рН водной & $\begin{array}{c}7,5 \\
\text { вытяжки, ед. рН }\end{array}$ & $\begin{array}{c}7,3 \\
\pm 0,4\end{array}$ & \\
\hline Подвижная форма металлов: & $\begin{array}{c}3,08 \\
\pm 0,32\end{array}$ & $\begin{array}{c}3,21 \\
\pm 0,9\end{array}$ & 3 \\
\hline Медь, мг/кг & $\begin{array}{c}0,86 \\
\pm 0,26\end{array}$ & $\begin{array}{c}1,76 \\
\pm 0,53\end{array}$ & 32 \\
\hline Свинец, мг/кг & $\begin{array}{c}79,04 \\
\pm 23,71\end{array}$ & $\begin{array}{c}91,76 \\
\pm 27,53\end{array}$ & 5 \\
\hline Кобальт, мг/кг & $\begin{array}{c}2,24 \\
\pm 0,67\end{array}$ & $\begin{array}{c}3,48 \\
\pm 1,04\end{array}$ & 1500 \\
\hline Марганец, мг/кг & менее 0,05 & менее 0,05 & 4 \\
\hline Никель, мг/кг & $\begin{array}{c}6,2 \\
\pm 1,9\end{array}$ & $\begin{array}{c}5,5 \\
\pm 1,7\end{array}$ & 2 \\
\hline Кадмий, мг/кг & \multicolumn{3}{|c|}{2} \\
\hline
\end{tabular}

Пропитывание нефтью и нефтепродуктами почвенной массы приводит к активным изменениям химического состава, свойств и структуры почвы. Прежде всего, это сказывается на гумусовом горизонте: количество углеводорода в нем резко увеличивается, но ухудшается свойство почв как питательного субстрата для растений [16]. В пробе почвы, отобранной с территории предприятия, процент гумуса равен 0,6, что в десятки раз меньше среднего содержания гумуса в верхнем горизонте почв. В образце № 2 запасы гумуса составляют 2,7; это также свидетельствует о низком плодородии почвенного покрова.

Анализ динамики рН пробы почвы загрязненного участка показал, что показатель $\mathrm{pH}$ в образце № 1 составил 7,3, а в образце № 2 - 7,5. Можно сделать вывод, что в присутствии нефти и нефтепродуктов в сочетании с растительными остатками преобладают слабощелочные почвы.

Показатель содержания нефтепродуктов в пробах почв образца № 1 составил 315,28 мг/кг, а в образце № $2-108,08$ мг/кг. Эти показатели являются фоновыми, то есть безопасными. Безопасным уровнем загрязнения почвогрунтов нефтепродуктами рекомендуют считать уровень, при котором ни одно из негативных последствий не наступает вследствие загрязнения почвы нефтепродуктами [17].
Также был проведен анализ на содержание тяжелых металлов. По степени опасности влияния на живые организмы тяжелые металлы делят на 3 класса:

1 класс - особо токсичные: мышьяк, кадмий, ртуть, свинец, селен, цинк, титан;

2 класс - токсичные: кобальт, никель, молибден, медь, сурьма, хром;

3 класс - слаботоксичные: барий, ванадий, вольфрам, марганец, стронций.

Большинство химических элементов входят в состав минералов и являются минералообразующими. Процессы превращения минералов в почве самые разнообразные: выветривание, окисление, гидратация, растворение. В дальнейшем образуются вторичные минералы, главным образом глинистые, которые определяют минеральную часть почв [18].

В результате исследований определено, что содержание кадмия и кобальта превышает ПДК, что обусловлено интенсивными техногенными нагрузками из-за близкого расположения предприятий и особенностей рельефа, что способствует оседанию основных выбросов предприятий. Повышенное содержание кадмия приводит к нарушению активности основных ферментов, к угнетению фотосинтеза, снижению проницаемости клеточных мембран, осложнениям в поступлении и метаболизме в растениях цинка, меди, марганца, никеля, селена, кальций, магний, фосфор. Фитотоксичность кобальта может проявляться в виде недоразвития цветов, ухудшения либо полной потери всхожести семян [19; 20]. В образце № 1 концентрация меди незначительно превышает предельно допустимо значение. Из всех анализируемых ионов металлов марганец и свинец имеют стабильно низкие концентрации. Такие элементы, как никель, свинец, марганец, не превышают ПДК.

\section{Bыводы}

Проведенные исследования показали, что почвенный слой территории нефтегазодобывающего предприятия характеризуется слабощелочной реакцией, отличается низким плодородием и содержанием гумуса, содержание нефтепродуктов не превышает ПДК. Концентрации некоторых тяжелых металлов $(\mathrm{Cu}, \mathrm{Pd}, \mathrm{Mn}, \mathrm{Ni})$ также являются безопасным. Тревожная ситуация сложилась с концентрацией кадмия и кобальта. Однако уровень фитоксичности анализируемых проб почвы был определен как высокий.

\section{СПИСОК ЛИТЕРАТУРЫ:}

1. Гриценко А.И., Акопов Г.С., Максимов В.М. Экология. Нефть и газ. М.: Наука, 1997. 598 с.

2. Каюкова Г.П., Гарейшина А.3., Егорова К.В. Нефти и нефтепродукты - загрязнители почвы // Химия и технология топлив и масел. 1999. № 5. C. $37-43$.

3. Алехин В.Г., Емцев В.Т., Рогозина Е.А., Фахрутдинов А.И. Биологическая активность и микробиологическая рекультивация почв, загрязненных нефтепродуктами // Биологические ресурсы и природопользование: сборник научных трудов. Нижневартовск: Изд-во Нижневартовского пед. ин-та, 1998, Вып. 2. С. 95-105.

4. Сафонникова С.М. Гигиеническая оценка почвы в районе размещения крупного нефтехимического 
комплекса и регламентация в ней некоторых токсических загрязнителей: автореф. дис. ... канд. биол. наук. М., 1991. 23 с.

5. Киреева Н.А., Тарасенко Е.М. Биотестирование как метод оценки загрязнения почв нефтью // Экология и промышленность России. 2004. Февраль. С. 26 29.

6. Киреева Н.А., Кабиров Т.Р., Дубовик И.Е. Комплексное биотестирование нефтезагрязненных почв // Теоретическая и прикладная экология. 2007. № 1. C. $65-69$.

7. ГОСТ 17.4.4.02-84. Охрана природы. Почвы. Методы отбора и подготовки проб для химического, бактериологического, гельминтологического анализа.

8. Логинов О.Н. Биотехнологические методы очистки окружающей среды от техногенных загрязнений. Уфа: Реактив, 2000. 100 с.

9. Салангинас Л.А. Изменение агрохимических и агрофизических характеристик почвы под влиянием нефтяного загрязнения // Биологическая рекультивация нарушенных земель: мат-лы междунар. совещания. Екатеринбург: УрО РАН, 2003. С. 278-283.

10. Сулейманов Р.Р., Назырова Ф.И. Изменение буферности почв при загрязнении нефтепромысловыми водами и сырой нефтью // Вестник ОГУ, 2007, № 4. С. 133-139.

11. Ашихмина Т.Я. Школьный экологический мониторинг: учебно-методическое пособие. М.: Агар, 2000. 386 c.

12. Середина В.П., Андреева Т.А. Экологические последствия нефтяного загрязнения почвенного покрова районов нефтедобычи // Проблемы и практика инженерного образования: труды VI международной научно-практической конференции. Томск: Изд-во ТПУ, 2004. С. 40-41.
13. Метод определения всхожести. ГОСТ 1203884. Семена сельскохозяйственных культур. М.: Издво стандартов, 1985. 57 с.

14. Koneva V., Kozlov K., Protopopov N., Andreyeva T. Phytotoxicity of soil contaminated by oil hydrocarbons // 14th Annual Meetling of SETAC Europe «Environmental Science Solutions. A Pan-European Perspective», 18-22 April 2004. Prague, Czech Republic, 2004. P. 247.

15. Санитарные правила и нормы СанПиН 2.1.7.1287-03 Санитарно-эпидемиологические требования к качеству почвы.

16. Андреева Т.А., Середина В.П. Изменение гумусного состояния почв под влиянием нефтяного загрязнения // Вестник Томского государственного университета. Приложение: материалы III всероссийской научной конференции «Современные проблемы почвоведения и оценки земель Сибири», 1315 сентября, г. Томск. 2005. № 15. С. 174-175.

17. Андреева Т.А. Интегральная оценка воздействия нефтяного загрязнения на параметры химического и биологического состояния почв таежной зоны Западной Сибири: автореф. дис. ... канд. биол. наук: 03.00.27. Томск, 2005. 26 с.

18. Большаков В.А., Борисочнина Т.И., Краснова Н.М. Нормирование загрязняющих веществ в почве // Химизация сельского хозяйства. 1991. № 9. C. $10-14$.

19. Назаров А.В., Илларионов С.А. Изучение причин фитотоксичности нефтезагрязненных почв // Письма в международный научный журнал «Альтернативная энергетика и экология». 2005. № 1. С. 6065.

20. Колесников С.И., Казеев К.Ш., Вальков В.Ф. Экологические последствия загрязнения почв тяжелыми металлами: монография. Ростов-на-Дону: Издво СКНЦ ВШ, 2000. 232 с.

\section{ASSESSMENT OF OIL COMPANIES IMPACT ON THE ECOLOGICAL STATUS OF SURROUNDING AREA SOILS}

Sultanova Milyausha Ilnurovna, student of Biology and Chemistry Faculty

Shmelev Nikolai Aleksandrovich, candidate of biological sciences, associate professor of Biology and Ecology Department

Islamova Aysylu Airatowna, candidate of biological sciences, associate professor of Biology and Ecology Department

Birsk branch of Bashkir State University (Birsk, Republic of Bashkortostan, Russian Federation)

Abstract. The paper analyzes the study results of the soil layer on the territory of oil and gas companies. Assessment of anthropogenic impact of oil on key chemical and biological parameters of soil is given on the basis of experimental research on the territory of the enterprise. The objects of the study was background (uncontaminated) and contaminated soil. The impact of oil pollution in natural conditions was studied by means of mapping properties of contaminated soils with their background counterparts. Soil cover is the main element of the landscape - the first assumes the «environmental impact». Because of mechanical disturbance and chemical pollution there is a gradual degradation of the soil, which has become one of the major environmental problems of oil and gas complex. The research was conducted in April-May 2017. The analysis shows that the morphological characteristics of the soil have changed significantly. The analysis of the soil phytotoxicity shows a high degree of soil phytotoxicity. The percentage of humus is less than the average content in the upper soil horizon. The analysis of the chemical composition shows a relatively low level of soil contamination with heavy metals, the exception was the concentration of cadmium and cobalt. The oil content does not exceed the MPC.

Keywords: soil; oil and gas enterprise; structure of soils; laboratory tests; comparative analysis; heavy metals; morphological characteristics of soils; petroleum products; phytotoxicity; watercress; bioindication; physicalchemical methods of analysis; maximum permissible concentration. 